\title{
Cholinergic Inputs from Basal Forebrain Add an Excitatory Bias to Odor Coding in the Olfactory Bulb
}

\author{
Markus Rothermel, ${ }^{1}$ Ryan M. Carey, ${ }^{1}$ Adam Puche, ${ }^{2}$ Michael T. Shipley, ${ }^{2}$ and Matt Wachowiak ${ }^{1}$ \\ ${ }^{1}$ Department of Neurobiology and Anatomy, Brain Institute, University of Utah, Salt Lake City, Utah 84103, and ${ }^{2}$ Department of Anatomy and \\ Neurobiology, Program in Neuroscience, University of Maryland School of Medicine, Baltimore, Maryland 21201
}

Cholinergic modulation of central circuits is associated with active sensation, attention, and learning, yet the neural circuits and temporal dynamics underlying cholinergic effects on sensory processing remain unclear. Understanding the effects of cholinergic modulation on particular circuits is complicated by the widespread projections of cholinergic neurons to telencephalic structures that themselves are highly interconnected. Here we examined how cholinergic projections from basal forebrain to the olfactory bulb (OB) modulate output from the first stage of sensory processing in the mouse olfactory system. By optogenetically activating their axons directly in the $0 B$, we found that cholinergic projections from basal forebrain regulate $\mathrm{OB}$ output by increasing the spike output of presumptive mitral/tufted cells. Cholinergic stimulation increased mitral/tufted cell spiking in the absence of inhalation-driven sensory input and further increased spiking responses to inhalation of odorless air and to odorants. This modulation was rapid and transient, was dependent on local cholinergic signaling in the $\mathrm{OB}$, and differed from modulation by optogenetic activation of cholinergic neurons in basal forebrain, which led to a mixture of mitral/tufted cell excitation and suppression. Finally, bulbar cholinergic enhancement of mitral/tufted cell odorant responses was robust and occurred independent of the strength or even polarity of the odorant-evoked response, indicating that cholinergic modulation adds an excitatory bias to mitral/tufted cells as opposed to increasing response gain or sharpening response spectra. These results are consistent with a role for the basal forebrain cholinergic system in dynamically regulating the sensitivity to or salience of odors during active sensing of the olfactory environment.

Key words: acetylcholine; mitral cell; modulation; odor coding; optogenetics

\section{Introduction}

The acquisition and processing of sensory information is rapidly modulated during behavior. In the olfactory system, substantial modulation of incoming sensory information occurs in the olfactory bulb (OB), which receives centrifugal innervation from classical neuromodulatory centers and olfactory cortical areas (Shipley and Adamek, 1984; Petzold et al., 2009; Boyd et al., 2012; Kato et al., 2012; Ma and Luo, 2012; Markopoulos et al., 2012). As an obligatory link between sensory neurons and cortical targets, modulation of $\mathrm{OB}$ output affects sensory processing at all subsequent stages and can shape odor perception (Mandairon et al., 2008; Chaudhury et al., 2009). Cholinergic projections originating in the basal forebrain are a major source of modulatory input to the OB. In other modalities, cholinergic modulation can enhance sensory processing by increasing the gain, sensitivity, or reliability of neural re-

Received Dec. 2, 2013; revised Feb. 21, 2014; accepted Feb. $22,2014$.

Author contributions: M.R., M.T.S., and M.W. designed research; M.R. performed research; R.M.C., A.P., and M.T.S. contributed unpublished reagents/analytic tools; M.R. analyzed data; M.R. and M.W. wrote the paper.

This work was supported by the NIH (Grant DC10915) and the DFG (to M.R.). We thank C. Zabawa for technical support, T. Cenier for assistance with control optogenetics experiments and data analysis code, and S. Taha and A. Yamaguchi for assistance with statistical analyses.

The authors declare no competing financial interests.

Correspondence should be addressed to Matt Wachowiak, Department of Neurobiology and Anatomy, Brain Institute, University of Utah, Salt Lake City, UT 84103. E-mail: matt.wachowiak@utah.edu.

DOI:10.1523/JNEUROSCI.5026-13.2014

Copyright $\odot 2014$ the authors $\quad 0270-6474 / 14 / 344654-11 \$ 15.00 / 0$ sponses to sensory stimuli (Sarter et al., 2005; Disney et al., 2007; Goard and Dan, 2009), and transient increases in cholinergic input to sensory cortex may underlie the changes in sensory signal detection that are the hallmark of heightened attention (Parikh and Sarter, 2008). Thus, modulation of OB processing by descending cholinergic projections may be critical in shaping how odor information is processed during behavior.

Prior studies have implicated cholinergic modulation in the $\mathrm{OB}$ in enhanced odor coding by mitral/tufted cells (MTCs), the major OB output neurons, and improved odor discrimination ability (Doty et al., 1999; Cleland et al., 2002; Mandairon et al., 2006; Chaudhury et al., 2009; Li and Cleland, 2013). One recent study reported that optogenetic activation of cholinergic neurons in basal forebrain inhibited spontaneous activity and preferentially suppressed weak sensory responses in MTCs, sharpening their odorant response spectra (Ma and Luo, 2012). However, the neural pathways underlying this modulation remain unclear because basal forebrain cholinergic neurons project across the limbic system and cortex (Záborszky et al., 2012) and target olfactory cortical areas that themselves strongly modulate OB circuitry (Woolf et al., 1984; Carlsen et al., 1985; Linster et al., 1999; Zimmer et al., 1999; Boyd et al., 2012; Markopoulos et al., 2012). In addition, other studies that electrically stimulated basal forebrain have reported enhanced spontaneous activity in MTCs (Kunze et al., 1991, 1992b; Zhan et al., 2013). Finally, the temporal dynam- 
ics of modulation by cholinergic projections from basal forebrain to the $\mathrm{OB}$ are poorly characterized.

We examined how cholinergic projections to the OB shape MTC activity by optogenetically activating the axons of cholinergic neurons projecting from basal forebrain to the OB. Optical stimulation of cholinergic axons in the OB caused a robust enhancement of spontaneous and sensory-evoked MTC excitation. This enhancement was dynamic, with transient activation of cholinergic fibers leading to transient modulation in the OB. Enhanced excitation in odorant-evoked responses occurred independent of the strength or even polarity of the response, consistent with cholinergic inputs to the $\mathrm{OB}$ adding an excitatory bias to MTC activity instead of altering response gain or sharpening response spectrum. These results suggest that cholinergic projections to the $\mathrm{OB}$ may rapidly modulate olfactory sensitivity during behavior.

\section{Materials and Methods}

Animals. Experiments were performed on male and female mice expressing Cre recombinase (ChAT-Cre mice) or Channelrhodopsin2(H134R)EYFP (ChAT-ChR2 mice) under control of the choline acetyltransferase (ChAT) promoter (Rossi et al., 2011; Zhao et al., 2011). Both lines were obtained from The Jackson Laboratory (ChAT-Cre, stock \#006410; ChAT-ChR2, stock \#014546)). ChAT-Cre mice were homozygous or were hemizygous offspring of crosses with the Cre-dependent tdTomato reporter line Ai9 (Jax stock \#007905). ChAT-ChR2 mice were maintained and used as hemizygotes. All animals were $<6$ months of age by completion of data collection. Mice were housed up to three per cage and kept on a $12 \mathrm{~h}$ light/dark cycle. Food and water were available ad libitum. All animal procedures were performed following the National Institutes of Health Guide for the Care and Use of Laboratory Animals and were approved by the University of Utah Institutional Animal Care and Use Committee.

Viral vector expression. ChR2 expression in cholinergic horizontal limb of the diagonal band of Broca (HDB) neurons was achieved using the recombinant viral vector AAV2/5.EF1a.DIO.hChR2(H134R)-EYFP. WPRE.hGH (University of Pennsylvania Viral Vector Core; reported viral titer, $\left.6.7 \times 10^{11}-2.0 \times 10^{13}\right)$, injected at the following stereotaxic coordinates relative to bregma (in $\mathrm{mm}$ ): +0.74 anteroposterior, 0.65 mediolateral, -4.8 dorsoventral. For injection, mice were anesthetized with ketamine $(70 \mathrm{mg} / \mathrm{kg}$ ) and medetomidine $(1 \mathrm{mg} / \mathrm{kg}$, Domitor; Pfizer) or isoflurane (1\%) and placed in a stereotaxic headholder, and a circular craniotomy $(\sim 1 \mathrm{~mm})$ was made over the injection site. Deep-brain injections were performed using a 33 gauge metal needle (Hamilton) and a programmable syringe controller (QSI; Stoelting) at a rate of $0.1 \mu \mathrm{l} / \mathrm{min}$. We injected large volumes of virus $(0.5-1 \mu \mathrm{l})$ to achieve widespread infection. Mice received atipamezole (Antisedan, $1 \mathrm{mg} / \mathrm{kg}$, s.c.; Pfizer) at the end of surgery to accelerate recovery from anesthesia. Mice were given carprofen (Rimadyl, $5 \mathrm{mg} / \mathrm{kg}$; Pfizer) as an analgesic immediately before surgery, and carprofen-supplemented food ( $2 \mathrm{mg} /$ tablet $)$ was provided for $4 \mathrm{~d}$ after surgery. Mice were single housed after surgery and used $14-56 \mathrm{~d}$ after virus injection.

Olfactometry. Odorants were presented as dilutions from saturated vapor (s.v.) in cleaned, humidified air using a custom olfactometer under computer control (Bozza et al., 2004; Verhagen et al., 2007). Odorants were presented for $10 \mathrm{~s}$. All odorants were obtained at $95-99 \%$ purity from Sigma-Aldrich and stored under nitrogen. We used mixtures of six to seven odorants (at 1-3\% s.v.) to screen for responsive MTCs. Once target units were identified, we switched to the lowest effective concentration $(0.1-1 \%$ s.v.) of one the following monomolecular odorants: propyl acetate, acetophenone, hexanal, isoamyl acetate, methyl benzoate, ethyl butyrate, 2-hexanone, methyl valerate, butyl acetate, isovaleric acid, or heptanal.

Extracellular recordings and optical stimulation. For MTC unit recordings, mice were anesthetized with pentobarbital $(50 \mathrm{mg} / \mathrm{kg}$ ) or urethane $(1.3 \mathrm{~g} / \mathrm{kg})$ and placed in a stereotaxic device. Body temperature was maintained at $37^{\circ} \mathrm{C}$. A double tracheotomy was performed, and an arti- ficial inhalation paradigm was used to control air and odorant inhalation independent of respiration (Wachowiak and Cohen, 2001; Spors et al., 2006). A small $(\sim 1 \times 1 \mathrm{~mm})$ craniotomy was performed over one OB, and the dura was removed. Extracellular recordings were obtained from OB units using either a 16-channel electrode (A1x16-5mm50-413-A16; NeuroNexus) and an RZ5 digital acquisition system [Tucker Davis Technologies (TDT) ] or a single-channel tungsten microelectrode $(2.0 \mathrm{M} \Omega$ at $1 \mathrm{kHz}$; WE3PT12.0F3, MicroProbes) amplified with a BMA-931 amplifier and Super-Z headstage (CWE), bandpass filtered from $1 \mathrm{~Hz}$ to 10 $\mathrm{kHz}$, and digitized at $20 \mathrm{kHz}$ using a Micro1401 MkII DAQ board and Spike2 software (Cambridge Electronic Design). Additional high-pass filtering was done in Spike2 at a cutoff frequency of $200 \mathrm{~Hz}$. For the multichannel recordings, spikes were detected and digitized on all 16 channels. Custom scripts in TDT software or Spike2 were used to control odorant presentation. Recordings from presumptive MTCs were obtained and selected as described by Carey and Wachowiak (2011). Briefly, we selected only units that appeared well isolated, in the vicinity of the mitral cell layer, and that showed clear spiking activity in the absence of odorant. Electrode depth was monitored with a digital micromanipulator (MP-225; Sutter Instruments). Except for the pharmacology experiments, data were collected from multiple penetrations per animal, and all recording sites were confined to the dorsal OB. Units were tested with up to seven odorants. Odorant alone ("baseline") and odorant plus optical stimulation trials (at least three trials each) were interleaved for all odorants (interstimulus interval, $70 \mathrm{~s}$ ). Recordings with at least five repeated trials of each were subject to unit-by-unit statistical analysis as described below. For the pharmacology experiments, the cholinergic antagonists scopolamine (1 mM; Sigma-Aldrich) and mecamylamine (1 mM; SigmaAldrich) were applied to the dorsal surface of the olfactory bulb as in previous studies (McGann et al., 2005; Pírez and Wachowiak, 2008).

For optical OB stimulation, light was presented as a single $10 \mathrm{~s}$ pulse either alone or simultaneous with odorant presentation using a $470 \mathrm{~nm}$ LED and controller (LEDD1B; Thorlabs) and a $1 \mathrm{~mm}$ optical fiber positioned within $3 \mathrm{~mm}$ of the dorsal $\mathrm{OB}$ surface. The light power at the tip of the fiber was between 1 and $10 \mathrm{~mW}$. Optical stimulation of HDB was delivered via a $200 \mu \mathrm{m}$ optical fiber positioned at HDB (same coordinates as above except the fiber was positioned slightly dorsal to the injection site), and light was generated by a $473 \mathrm{~nm}$ DPSS laser (Laserwave). In all experiments, fiber localization within or close to HDB was verified histologically. We replicated the optical pulse train from Ma and Luo (2012), consisting of $15 \mathrm{~ms}$ pulses repeated at $50 \mathrm{~Hz}$ for $30 \mathrm{~s}$, and using a maximal power density of $20 \mathrm{~mW} / \mathrm{mm}^{2}$. Optical stimulation trials were interleaved with trials with no stimulation. In all cases, the intertrial interval was at least $60 \mathrm{~s}$.

Data analysis. Action potential waveforms with a signal-to-noise ratio of at least $4 \mathrm{SD}$ above baseline noise were thresholded and saved to a disk, and single units were further isolated using off-line spike sorting (OpenSorter; TDT). Multiple units present on the same channel were isolated with user supervision using the Bayesian or (in fewer cases) K-Means cluster cutting algorithms in OpenSorter. Waveforms were classified as a single neuron if they fell within discrete clusters in a space made up of principle components 1 and 2. Unit isolation was further confirmed by the distribution of interspike intervals. After spike sorting and generation of spike rasters, subsequent analyses were performed using custom scripts in Matlab.

Responses to optical or odorant stimulation were analyzed differently depending on the experimental paradigm. Stimulation effects on spontaneous spike rate in the absence of artificial inhalation were measured by calculating spikes per second (hertz) for the $9 \mathrm{~s}$ before or during stimulation. Effects of optical stimulation on spiking during inhalation of clean air were measured for units showing significant modulation in firing rate by inhalation (i.e., "sniff"). Sniff modulation was assessed by constructing "sniff-triggered" spike rate histograms (PSTHs) from spike counts in 50 or $100 \mathrm{~ms}$ time bins compiled across all prestimulation trials, and units were included for analysis if the maximum spike rate in a bin was at least two times the minimum spike rate for the PSTH. Subsequently, inhalation-evoked responses were measured by averaging the number of spikes per $1 \mathrm{~s}$ period after each inhalation in the nine inhalations before or during stimulation and across multiple trials (minimum of three trials 
in each condition for all units). Odorantevoked responses were measured as changes in the mean number of spikes evoked per $1 \mathrm{~s}$ inhalation cycle ( $\Delta$ spikes/sniff) during odorant presentation, relative to the same number of inhalations just before odorant presentation. For statistical analysis, significance for changes in firing rate for baseline versus optical stimulation was tested on a unit-by-unit basis using the Mann-Whitney $U$ test on units tested with five or more trials per condition.

Histology. Accurate targeting of HDB by virus injection and expression of ChR2-EYFP in axons within the OB was confirmed with post hoc histological analysis in all mice. Mice were overdosed with anesthetic and perfused with PBS followed by 4\% paraformaldehyde in PBS. Heads were postfixed overnight at $4^{\circ} \mathrm{C}$ before brains were extracted and stored in paraformaldehyde in PBS until they were processed further. Sections were analyzed with an Olympus wide-field or IX70F confocal laserscanning inverted microscope at $10 \times$ or $20 \times$ magnification.

\section{Results}

Optogenetic activation of cholinergic axons in the OB enhances MTC spontaneous spiking

We used a mouse line expressing Cre under control of the ChAT promoter (ChAT-Cre mice; Rossi et al., 2011) to selectively target cholinergic projections from basal forebrain to the OB. The cholinergic identity of Cre-expressing basal forebrain neurons in this line has been verified previously (Kalmbach et al., 2012). ChAT-Cre crossed with the Ai9

Cre-dependent tdTomato reporter line (Madisen et al., 2010) revealed cholinergic neurons throughout basal forebrain and ventral striatum (Fig. 1A). There was a high density of tdTomato-positive neurons in the HDB, the major source of cholinergic projections to the OB (Záborszky et al., 1986). We expressed ChR2(H134R)-EYFP selectively in cholinergic HDB neurons using a Cre-dependent viral expression vector targeted to HDB by stereotaxic injection (see Materials and Methods). Viral injection led to ChR2-EYFP expression on the somata and processes of neurons throughout HDB and, to a lesser extent, the vertical limb of the diagonal band of Broca, but few, if any, neurons in the striatum or other basal forebrain nuclei (Fig. $1 B$ ). To assess the effectiveness and specificity of viralmediated ChR2 expression, in five mice we injected virus in $\mathrm{HDB}$ of ChAT-Cre:tdTomato reporter crosses (Fig. 1C). We found a coexpression rate of $88.3 \pm 1.9 \%$ (mean \pm SD from five mice; of a total of 517 tdTomato-positive cells, 458 were also ChR2-EYFP positive) but very little evidence of ChR2 expression in ChATnegative neurons $(2.2 \pm 1.2 \%$, or 9 of 467 ChR2-EYFP-positive neurons, were tdTomato negative). This infection rate is similar to that reported for striatal cholinergic neurons using the same viral construct in ChAT-Cre mice (Witten et al., 2010) but substantially higher than that reported for cholinergic neurons in basal forebrain of mice receiving injections at P21 (Kalmbach et al., 2012), possibly reflecting differences in virus infection efficacy at different postnatal ages or in different basal forebrain nuclei. With sufficient incubation time after virus injection
B

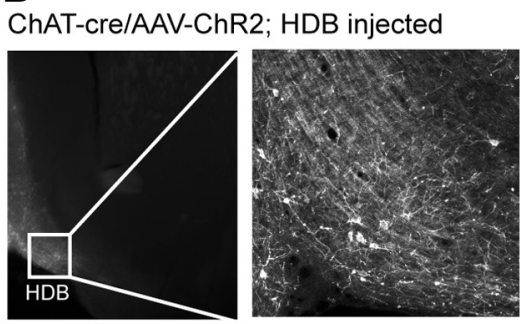

E

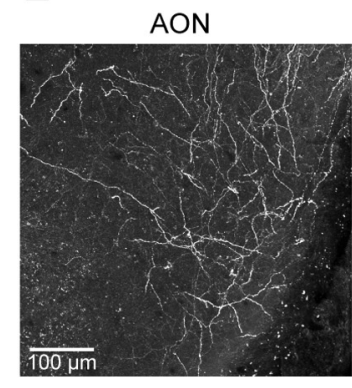

E
IPL

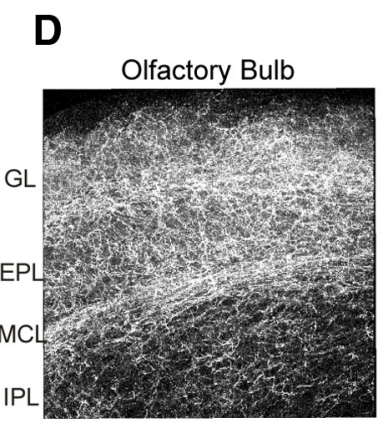

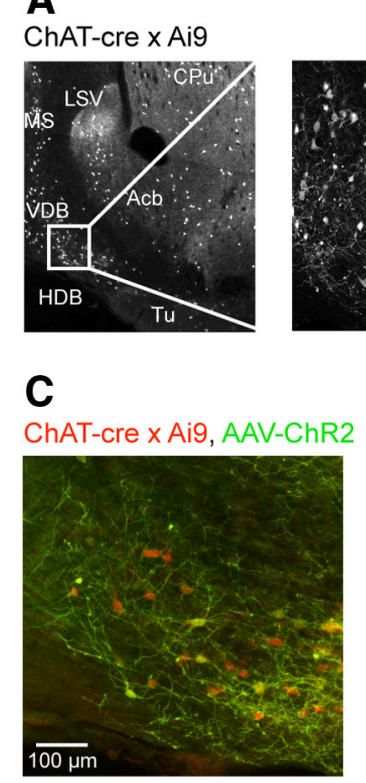

Figure 1. Selective targeting of cholinergic inputs from basal forebrain to the $O B$. $A$, Left, Cholinergic neurons in basal forebrain and striatum visualized in a ChAT-Cre:Rosa-tdTomato (Ai9) reporter cross. The coronal section was taken at $\sim 0.74$ bregma. Right,

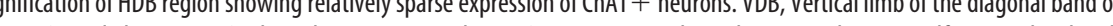
HDB region in this mouse showing extensive processes of ChAT + neurons. C, Double labeling with ChR2-EYFP and tdTomato

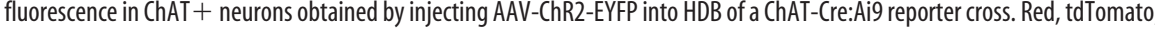
axon terminals in the OB imaged 4 weeks after AAV-ChR2-EYFP injection into HDB of a ChAT-Cre mouse. GL, glomerular layer; EPL, external plexiform layer; MCL, mitral cell layer; IPL, internal plexiform layer. $\boldsymbol{E}$, ChR2-EYFP fluorescence in axon terminals in anterior olfactory nucleus (AON) after AAV-ChR2-EYFP injection into HDB of a ChAT-Cre mouse.

(range, 21-56 d), ChR2-EYFP protein was apparent in cholinergic axons throughout the OB of ChAT-Cre mice, with the densest innervation in the glomerular, external plexiform, and mitral cell layers (Fig. 1D). ChR2-EYFP was also apparent, although sparser, in the anterior olfactory nucleus (Fig. $1 E$ ) and piriform cortex (not shown), consistent with previously reported cholinergic projections from HDB to these structures (Woolf et al., 1984; Linster et al., 1999; Záborszky et al., 2012).

To investigate modulation of early olfactory processing by cholinergic projections from $\mathrm{HDB}$ to $\mathrm{OB}$, we recorded from dorsally located presumptive MTCs in anesthetized mice while directing $473 \mathrm{~nm}$ light (1-10 $\mathrm{mW}$ total power) onto the dorsal OB surface (Fig. 2A). Artificial inhalation of air or odorant was controlled experimentally (see Materials and Methods). First, to assess the impact of cholinergic stimulation on MTC excitability in the absence of sensory input, we optically activated cholinergic axons without ongoing inhalation. In the absence of inhalation, MTCs show irregular spontaneous firing with no modulation by the respiratory cycle (Fig. 2A; Carey and Wachowiak, 2011; Courtiol et al., 2011). Optical stimulation significantly increased MTC spontaneous firing rate (Fig. $2 B$ ), from $0.8 \pm 3.1 \mathrm{~Hz}$ (mean $\pm \mathrm{SD}$ ) before stimulation to $1.2 \pm 4.2 \mathrm{~Hz}$ during stimulation $(n=57$ units from four mice; $p=1 \times 10^{-10}$, Wilcoxon signed rank test). In 44 of these cells, stimulation was repeated in a sufficient number of trials to support a test of significance on each unit (criterion, $n \geq 5$ trials; all other units tested with $n \geq 3$ trials). Nineteen of these units (43\%) showed statistically significant increases in firing rate when tested on a unit-by-unit basis (Mann-Whitney $U$ 
A

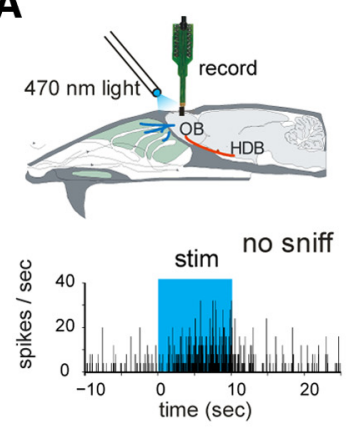

E

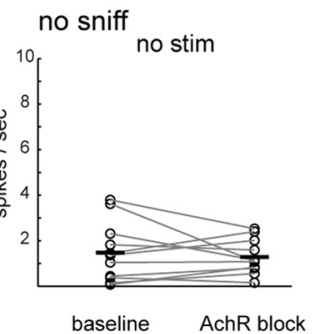

B

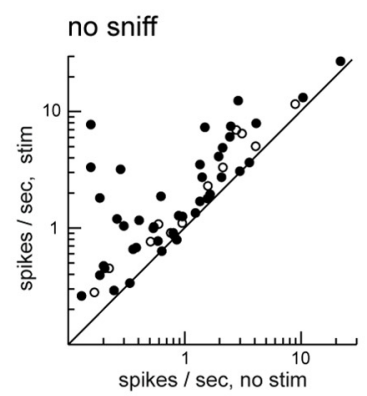

C
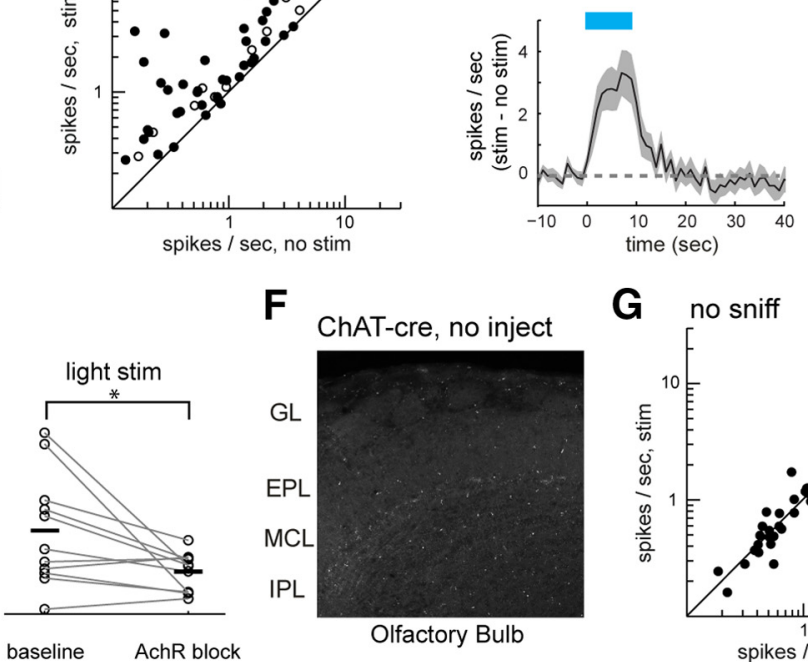

$\mathbf{F}_{\text {ChAT-cre, no inject }}$

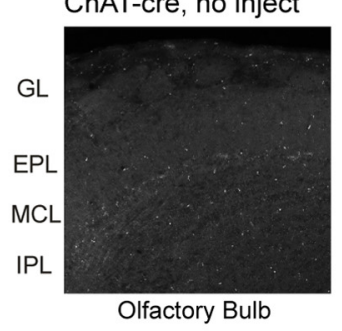

G

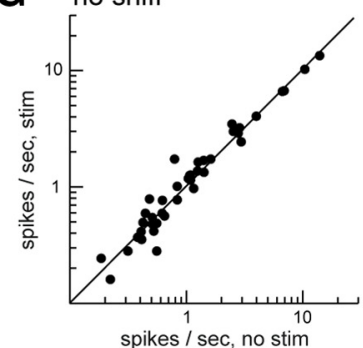

no sniff, urethane

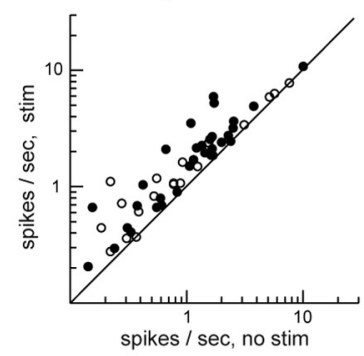

H

Figure 2. Optogenetic activation of cholinergic inputs to the OB enhances MTC excitability. $\boldsymbol{A}$, Top, Schematic of experimental approach. See Materials and Methods for details. Bottom, Spike rate histogram (bin width, $50 \mathrm{~ms}$ ) from a presumptive MTC showing spontaneous spiking in the absence of inhalation (no sniff). Spike rate increases during optical stimulation of the dorsal OB ("stim", blue shaded area). B, Plot of spontaneous firing rate in the 9 s before (no stim) and during (stim) optical stimulation for all tested units ( $n=57$ ). Filled circles indicate units subjected to a unit-by-unit test for significant effects of HDB stimulation ( $\geq 5$ trials per condition per unit). Open circles indicate units tested with three to four trials. $\boldsymbol{C}$, Time course of change in firing rate (mean \pm SEM across all units) during optical stimulation (blue bar). The trace indicates change in mean spike rate in $1 \mathrm{~s}$ bins relative to the mean rate before stimulation. The time axis is relative to time of stimulation onset. $\boldsymbol{D}$, Plot of spontaneous firing rate of MTCs $(n=54)$ recorded in urethane-anesthetized mice before and during optical stimulation and analyzed as in $\boldsymbol{B}$. $\boldsymbol{E}$, Quantitative comparison of spontaneous firing rates at before (baseline) and after AchR blocker application measured before (no stim) and during (light stim) optical stimulation. Open circles, firing rates for individual units; filled bars, mean value. Lines connect the same unit across conditions. The asterisk indicates significant difference by two-way ANOVA (see Results). $\boldsymbol{F}$, 0 B section from a control, uninjected (no inject) ChAT-Cre mouse showing absence of axonal fluorescence in the $O B$. Laser power and detector gain was set higher to confirm absence of axonal fluorescence, revealing autofluorescent monocytes throughout the $0 B$ (bright points). GL, Glomerular layer; EPL, external plexiform layer; MCL, mitral cell layer; IPL, internal plexiform layer. G, Plot of spontaneous firing rate of MTCs in control mice before and during optical stimulation of the $O B$ ( $n=41$ units), recorded and analyzed as in $\boldsymbol{B}$. $\boldsymbol{H}$, Time course of firing rate change across all recorded MTCs during optical stimulation in control mice.

test); none showed a decrease. Among these 19 units, the median firing rate increased by $2.1 \pm 2.4 \mathrm{~Hz}$. Across the population of all recorded units, the increase in spontaneous firing rates persisted for the duration of the $10 \mathrm{~s}$ optical stimulation and returned to prestimulus levels within 5-10 s after stimulation ceased (Fig. $2 C)$. To test whether the enhancement of mitral cell spiking after optical stimulation of the HDB was anesthesia dependent, we repeated the experiments in mice anesthetized with urethane. Under urethane, we also observed an optically induced increase in spontaneous MTC spike rate $(n=54$ units from two mice; $0.9 \pm 1.9 \mathrm{~Hz}$ before stimulation, $1.6 \pm 2.1 \mathrm{~Hz}$ during stimulation; $p=2 \times 10^{-10}$, Wilcoxon signed rank test), with 8 of 34 cells (24\%) tested on a unit-by-unit basis showing a significant increase and none showing a decrease in firing rate (Fig. 2D).

Activation of HDB axons in the olfactory bulb could result in back-propagation of action potentials to the soma and output to other targets of HDB and, potentially, indirect and noncholinergic modulation of $\mathrm{OB}$ activity. To address this possibility, we locally blocked nicotinic and muscarinic ACh receptors at the OB surface while optogenetically stimulating cholinergic axons. After applying the nicotinic and muscarinic ACh receptor antagonists mecamylamine and scopolamine (both at $1 \mathrm{~mm}$ ) to the dorsal OB surface, the optically evoked increase in spontaneous MTC firing was significantly reduced (Fig. 2E; 11 units from three mice; two-way ANOVA with drug and light as factors: light, $F_{(1,40)}=8.54, p=0.006$; drug, $\left.F_{(1,40)}=4.86, p=0.033\right)$, with 10 of 11 units showing a smaller optically evoked increase in spike rate. These results indicate that the optogenetically induced increase in spontaneous MTC spiking is mediated by local cholinergic signaling within the $\mathrm{OB}$.

In control (uninjected) ChAT-Cre mice (Fig. $2 F$ ), the same optical stimulation led to no significant change in spontaneous firing rate $(n=42$ units from two mice; $0.9 \pm 3.3 \mathrm{~Hz}$ before stimulation, $1.0 \pm 3.2 \mathrm{~Hz}$ during stimulation; $p=0.3817$, Wilcoxon signed rank test; Fig. $2 G$ ) and a slight decrease in firing after stimulation ceased (Fig. $2 H$ ). In additional recordings from wild-type mice, we found that spontaneous MTC firing was unaffected by continuous light stimulation at powers below $25 \mathrm{~mW}$ ( $n=9$ units from three mice; four of nine units showed a slight decrease in firing rate using continuous light stimulation at 25 $\mathrm{mW}$ ). Thus, the light-evoked increase in spontaneous MTC firing in ChR2-injected ChAT-Cre mice was attributable to cholinergic signaling mediated by the optogenetic activation of cholinergic axons in the $\mathrm{OB}$.

\section{Optogenetic activation of cholinergic axons in the $\mathrm{OB}$} enhances inhalation- and odorant-evoked MTC spiking Since HDB stimulation enhances MTC spontaneous spike generation, we hypothesized that inhalation-evoked MTC responses would also be enhanced. To test this, we investigated the effects of OB cholinergic activation on MTC responses during artificial inhalation of clean air. We selected units that showed clear inhalation-linked temporal patterning in spike output (see Materials and Methods; Fig. 3A), including 20 units from four mice. 
A

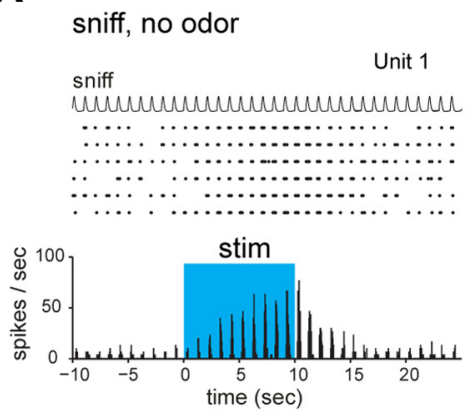

D

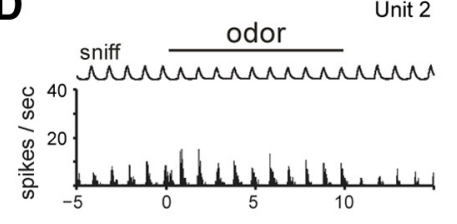

odor + stim

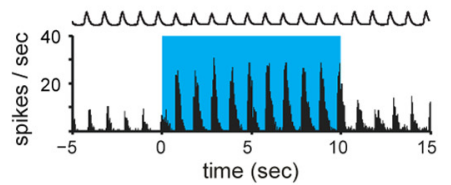

B

sniff, no odor

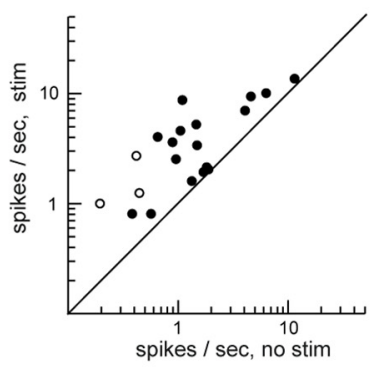

E

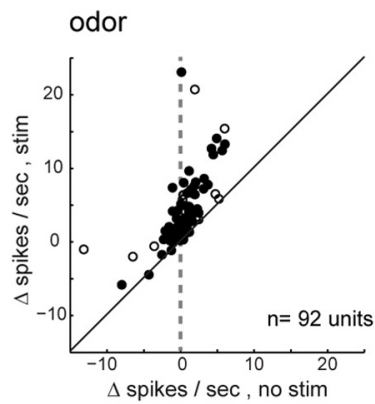

C

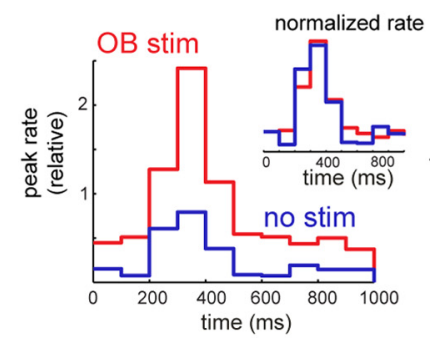

F
G

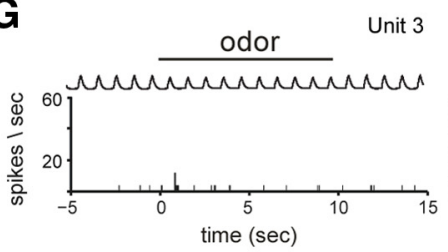

odor + stim

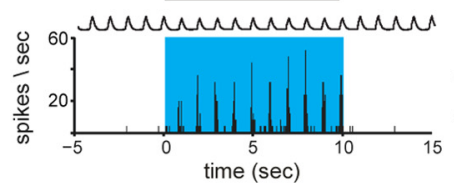

Unit 3
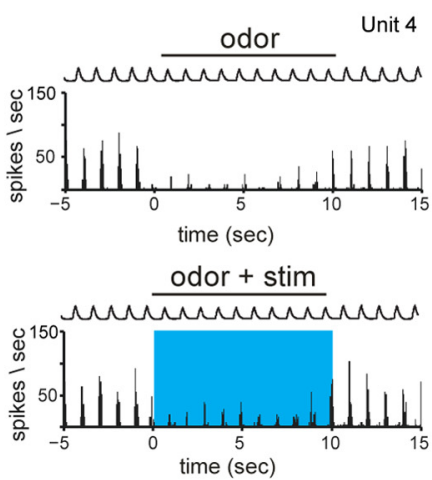

H

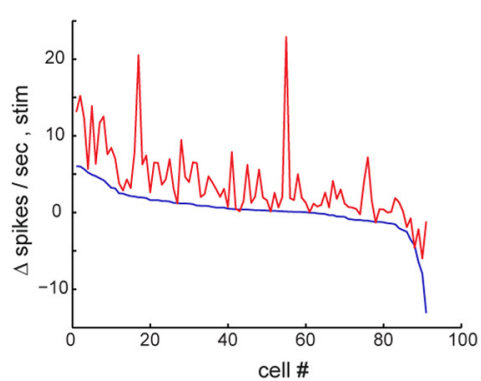

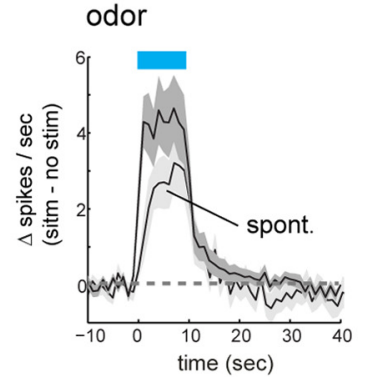

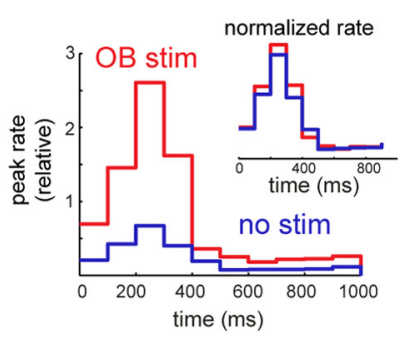

Figure 3. Optogenetic activation of cholinergic OB inputs enhances sensory-evoked excitation. $\boldsymbol{A}$, Spike raster and rate histogram of MTC spiking during inhalation of clean air and optical stimulation (blue shaded area) in six repeated trials. The spike rate was calculated per $50 \mathrm{~ms}$ bin. Inhalation-evoked spike rates increase during optical stimulation and return to baseline within $5-10$ s after stimulation ceases. The top trace (sniff) shows artificial inhalation as measured by a pressure sensor connected to the nasopharyngeal cannula. $\boldsymbol{B}$, Plot of inhalation-evoked firing rates during air inhalation, averaged for the nine inhalations just before (no stim) and after (stim) optical stimulation ( $n=20$ units). Data were analyzed and plotted as in Figure 2. C, Sniff-triggered spike histogram of MTC spikes aligned to the start of inhalation of clean air before (blue) and after (red) optical stimulation, normalized to the maximum bin in the no-stimulation condition. Bin width, $100 \mathrm{~ms}$. The histogram is compiled from all units, with firing rate normalized separately for each unit. Note that the relative increase in spike rate at the peak bin is larger than the relative increase of the baseline bins immediately after inhalation. Inset, Sniff-triggered histogram normalized to the maximum and minimum bin for both conditions independently, showing no change in spiking dynamics after OB stimulation. D, Odorant-evoked MTC spiking is enhanced by optical OB stimulation. This example MTC shows a moderately increased firing rate in response to odorant presentation in baseline conditions (top) and strongly increased odorant-evoked firing rates during optical stimulation (bottom). The histogram is the average of five trials. $\boldsymbol{E}$, Plot of odorant-evoked changes in MTC spiking ( $\Delta$ spikes/sniff) in the absence of (no stim) and during (stim) optogenetic stimulation of cholinergic afferents to the $0 B$ ( $n=92$ units). $F, 0$ dorant response magnitudes ( $\Delta$ spikes/s) plotted for baseline (blue) and optical stimulation (red) as a function of cell identity, sorted in order of magnitude of excitatory response in baseline conditions. Note that all units show an increase or no change in odorant-evoked excitation, including those that are suppressed during odorant presentation. Shown is the same dataset as in $E$. G, Spike histograms for two additional units showing that optical OB stimulation increases spike rate even for neurons that show a null (Unit 3, left) or suppressive (Unit 4, right) response to odorant. $\boldsymbol{H}$, Time course of effects of optical stimulation on odorant-evoked spike rate, averaged across all units. The blue bar shows time of optical stimulation and simultaneous odorant presentation. The darker trace shows mean change in odorant-evoked spike rate between trials with and without light stimulation, measured after each inhalation (at $1 \mathrm{~Hz}$ ); the shaded area indicates variance (SEM) around mean. The lighter trace (spont) shows light-evoked change in the spontaneous firing rate in the absence of inhalation, reproduced from Figure 2C.I, Sniff-triggered spike histogram of MTC spikes during odorant presentation in baseline conditions (blue) and during optical OB stimulation (red), normalized and plotted as in C. Inset, Sniff-triggered histogram normalized to the maximum and minimum bin for both conditions independently.

Because MTCs show no inhalation-linked patterning in the absence of artificial inhalation and inhalation without odorant elicits weak sensory inputs to the OB (Grosmaitre et al., 2007; Carey et al., 2009), we interpret inhalation-linked MTC activity as reflecting weak sensory-evoked responses. Mean spike rates averaged across the entire $1 \mathrm{~s}$ inhalation period (measured as spikes per sniff per second) were only slightly higher than those measured in the absence of inhalation $(1.2 \pm 2.7 \mathrm{~Hz}$, median $\pm \mathrm{SD})$. Optogenetic stimulation of bulbar cholinergic inputs increased inhalation-linked spiking of MTCs (Fig. 3A,B), consistent with optical activation effects observed on spontaneous spiking. Optical stimulation enhancement of spiking was highly significant 
across the population of recorded MTCs, with median spikes per sniff per second increasing from $1.2 \pm 2.7$ to $3.0 \pm 3.6$ during optical stimulation ( $p=0.00008$, Wilcoxon signed rank test), and was also robust at the level of individual MTCs, with 12 of 17 units subject to unit-by-unit analysis (70\%) showing a significant increase in spikes per sniff and 0 showing a decrease. Inhalationevoked spiking of these 12 cells increased by $3.2 \pm 1.8$ spikes/ sniff/s. The increase in inhalation-evoked MTC spiking was also dependent on cholinergic signaling in the $\mathrm{OB}$, as surface application of ACh receptor antagonists significantly reduced the difference in spike rate evoked by optical stimulation $(n=11$ units from three mice; $p=0.013$, Wilcoxon signed rank test). Examination of the pattern of MTC spiking relative to the start of inhalation in sniff-triggered spike histograms showed that cholinergic stimulation did not alter the temporal pattern of MTC responses relative to inhalation (Fig. $3 \mathrm{C}$ ), as the time bin of peak firing of the inhalation-evoked MTC spike burst did not change across the population of recorded units ( $p=0.7$, paired $t$ test comparing time bin of the peak of odorant-evoked firing rate for baseline vs optical stimulation). The sniff-triggered spike histograms also revealed that the effect of optical stimulation on inhalationevoked responses was not simply caused by the increase in baseline firing rates, but instead involved an additional increase in peak spike rate in the $100-300 \mathrm{~ms}$ after inhalation (Fig. 3C).

Since optical activation of HDB inputs to the bulb increased inhalation-linked MTC spiking consistent with enhancing weak sensory-evoked responses, we next evaluated the impact of bulbar cholinergic modulation on odorant responses by comparing MTC responses to odorant stimulation alone and when paired with optogenetic activation of cholinergic axons (Fig. 3D). Across all recorded MTCs ( $n=92$ cells from seven mice), bulbar cholinergic activation significantly increased MTC spiking during odorant presentation, with an increase from $1.4 \pm 2.6$ spikes/ sniff/s (median $\pm \mathrm{SD}$ ) during odorant presentation alone to $4.3 \pm 5.4 \mathrm{spikes} / \mathrm{sniff} / \mathrm{s}$ during odorant paired with light $(p=1 \times$ $10^{-16}$, Wilcoxon signed rank test; $n=92$ cells). Optical stimulation increased the odorant-evoked component of the MTC response (measured as $\Delta$ spikes/sniff/s relative to preodor presentation; Fig. 3E). Although 56 of 73 (76\%) individually tested units showed a significant increase in odorant-evoked spiking, none showed a decrease (Fig. $3 E, F$ ). The median increase in spike rate across these 56 cells was 4.3 spikes/sniff/s (from $0.7 \pm$ 3.2 to $5.0 \pm 12.3$ ). Indeed, activation of bulbar cholinergic inputs increased odorant-evoked responses even when the responses before optical activation were inhibitory or null (Fig. 3G). Finally, as with effects on spontaneous spiking, the enhancement of odorant-evoked MTC responses occurred rapidly, persisted for the duration of optical stimulation, and returned to prestimulation levels within $10 \mathrm{~s}$ after the end of optical stimulation (Fig. $3 H$ ). As with responses to inhalation of clean air, there was no change in the temporal patterning of MTC responses relative to inhalation (Fig. 3I; $p=0.2$, paired $t$ test; $n=92$ ). Finally, bulbar cholinergic stimulation enhanced MTC odorant responsiveness beyond that expected from its effect on spontaneous MTC spiking: peak spike rates in the 100-300 ms range after inhalation of odorant increased proportionally more than baseline rates just preceding the inhalation-evoked response (Fig. 3I), and, on average, the relative increase in odorant-evoked spike rates was larger than the increase in spontaneous spiking that occurred without inhalation (Fig. $3 \mathrm{H}$, compare "odor" with "spont" trace). Thus, transient activation of cholinergic axons in the OB leads to transient increases in odorant-evoked MTC excitation without grossly reorganizing inhalation-linked temporal patterns of activation.

\section{Optogenetic activation of cholinergic axons in the $\mathrm{OB}$ adds excitation to MTC odorant responses}

Previous theoretical and pharmacological studies have suggested that cholinergic modulation sharpens MTC response specificity by preferentially suppressing weak MTC responses and enhancing inhibitory responses (Chaudhury et al., 2009; Ma and Luo, 2012; Li and Cleland, 2013). Whereas the above results did not support these predictions, the experiments did not compare effects of cholinergic activation on responses with different odorants tested in the same cell and may have been biased toward analysis of strong excitatory responses. Thus, in a separate set of experiments, we measured responses of the same MTC to multiple odorants (see Materials and Methods for odorant panel) with and without optogenetic activation of cholinergic bulbar inputs (10 cells, three animals, 58 cell-odor pairs). Figure $4 A$ shows examples from two such recordings. Although the magnitude of the effect of bulbar cholinergic activation varied for different odorants, odorant-evoked spike rates nearly always increased during light stimulation, even when baseline responses were inhibitory (Fig. $4 A$, example 2). In fact, of 58 odor-cell pairs, only 3 showed a slight $(<0.5$ spikes/sniff/s $)$ reduction in odorantevoked spike rates during cholinergic activation. There was no significant relationship between the effect of cholinergic stimulation on odorant-evoked spike rates and the magnitude of the response under baseline conditions when odorant-cell responses $(n=58)$ were collapsed across units (Fig. 4B; Pearson's $r=0.12$; two-tailed, $p=0.35$ ), or when responses were analyzed based on the relative rank of the response within each unit (Fig. 4C; Spearman's $\rho=0.22$; two-tailed, $p=0.10$ ). Moreover, there was only a marginally significant difference in the effect of bulbar cholinergic activation on the bottom versus the top quartile of odorantevoked responses measured across the 10 units (Fig. $4 D$; unpaired Wilcoxon rank-sum test, $p=0.06 ; n=29$ cell-odor pairs). Thus, independent of relative odorant "strength" in exciting a MTC, stimulation of cholinergic fibers in the olfactory bulb broadly increased MTC excitability.

\section{Cholinergic enhancement of MTC excitation in ChAT- ChR2 mice}

Our findings contrast with those of a recent study that reported robust suppression of MTC spontaneous activity and preferential suppression of weak excitatory responses by optogenetic stimulation of cholinergic somata in basal forebrain of anesthetized transgenic mice expressing $\mathrm{ChR} 2$ under control of the ChAT promoter (ChAT-ChR2 mice; Ma and Luo, 2012). A recent report indicated that ChAT-ChR2 mice have altered cholinergic tone because of overexpression of the vesicular acetylcholine transporter (Kolisnyk et al., 2013), and ChR2 expression levels likely differ from virus-injected ChAT-Cre mice; viral-mediated expression of ChR2 in cholinergic neurons may also alter resting membrane potential, input resistance, and other parameters controlling neuronal excitability (Witten et al., 2010; Kalmbach et al., 2012). Thus, we tested whether intrabulbar stimulation of cholinergic inputs to the OB had a similar effect on MTC excitability in ChAT-ChR2 mice ( $n=2$ mice). ChR2-EYFP fluorescence in centrifugal axons in the OB was substantially weaker and sparser than in virus-injected ChAT-Cre mice but was detectable in all OB layers (Fig. 5A). Despite weaker axonal expression of ChR2, optical stimulation of the dorsal OB had similar effects in this mouse line, with cholinergic activation leading to a significant 

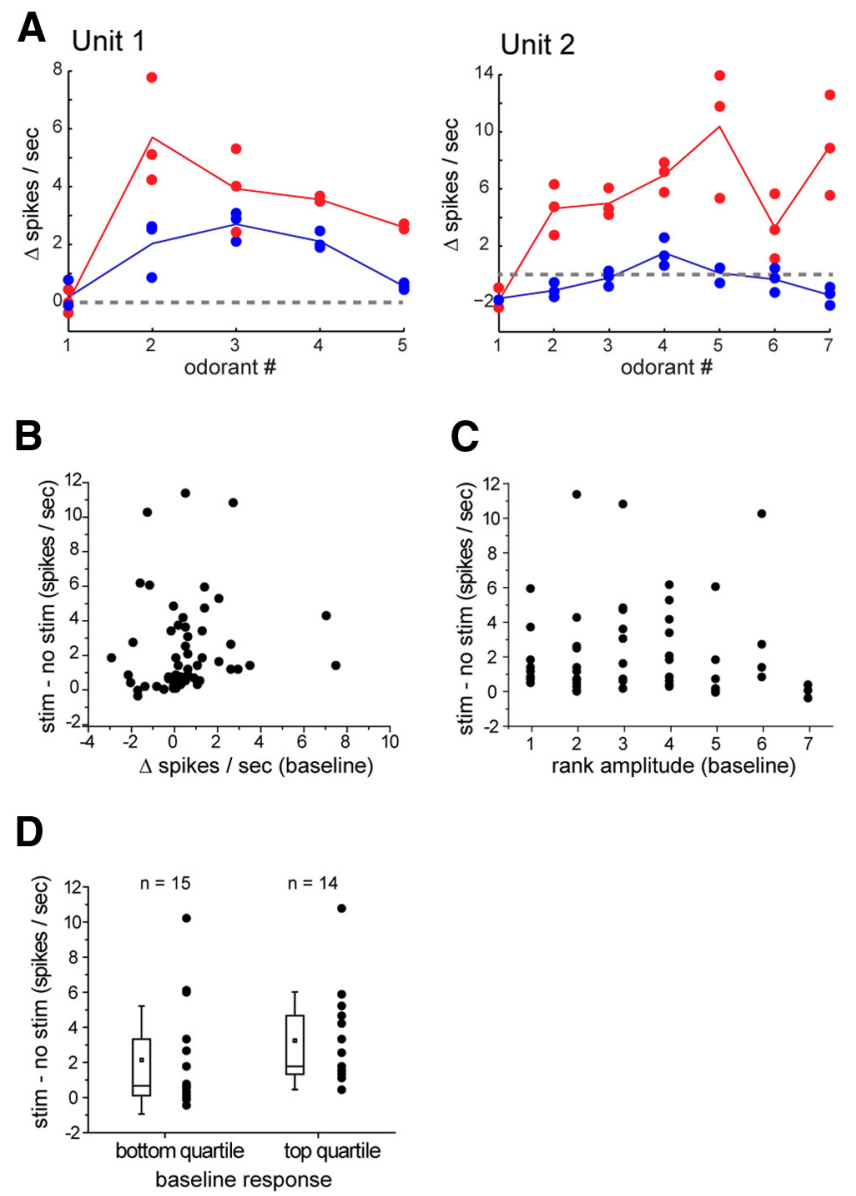

Figure 4. Optogenetic activation of cholinergic OB inputs enhances MTC odorant responses independent of absolute or relative odorant response strength. $A$, Effect of $O B$ optical stimulation on odorant response spectrum for two MTCs tested with five (left) or seven (right) odorants. Blue, Baseline response; red, response during optical stimulation. Odorants are ordered separately for each unit, with the strongest excitatory response in the baseline condition in the middle of the abcissa. For each unit, the effect of optical stimulation varies with odorant but is always excitatory, even for odorants that suppress spiking under baseline conditions (e.g., odorants 1, 2, 6, and 7 in example 2). Circles indicate firing rates for each trial; lines connect median responses across all tested trials. $\boldsymbol{B}$, Plot of optically induced change in odorant-evoked spike rate (stim - no stim) versus magnitude of the MTC response to odorant in baseline conditions $(\Delta$ spikes/s). Each point represents one cell- odorant pair. C, Ordinal plot of optically induced change in odorant-evoked spike rate (stim - no stim; same cell- odorant pairs as in $\boldsymbol{B}$ ) as a function of rank order of MTC excitation relative to all odorants tested for that cell. A rank of 1 indicates the strongest response of all tested odorants. D, Box plot comparing optically induced change in odorant-evoked spike rate (stim - no stim) for the strongest and weakest quartile of baseline odorant-evoked responses taken from all cell- odorant pairs. The box indicates median, $25-75$ th percentile ranges of the data, and whiskers indicate \pm 1 SD from the mean. Individual data points are shown to the right of each box.

increase in spontaneous activity in the absence of stimulation (Fig. $5 B ; n=24$ units; $p=2 \times 10^{-5}$, Wilcoxon signed rank test), MTC spiking during inhalation of clean air (Fig. $5 C ; n=34$ units; $p=4 \times 10^{-7}$, Wilcoxon signed rank test), and spiking during odorant presentation (Fig. $5 D ; n=33$ units; $p=2 \times 10^{-5}$, Wilcoxon signed rank test). Thus, activating cholinergic inputs to the OB increases MTC excitability in different mouse lines and with different modes of ChR2 expression.

These results suggest that mass activation of cholinergic neuron somata in the HDB may modulate $\mathrm{OB}$ activity differently than selectively activating HDB cholinergic terminals in the OB. To test this possibility, we recorded from presumptive MTCs in urethane-anesthetized ChAT-ChR2 mice and delivered optical stimulation to HDB (Fig. 5E). We used an optical pulse stimulation protocol identical to that reported to cause robust suppression of spontaneous MTC spiking in freely breathing mice (Ma and Luo, 2012) and measured spike rates during artificial inhalation of clean air to facilitate comparison with that study. Activating cholinergic neurons by optical stimulation of HDB had qualitatively different effects on MTCs compared with those observed with stimulation of HDB cholinergic terminals in the OB. First, across all recorded MTCs ( $n=33$ in two mice), the increase in firing rate during $30 \mathrm{~s}$ optical stimulation of HDB was negligible $(5.9 \pm 4.0 \mathrm{spikes/sniff/s} \mathrm{before} \mathrm{stimulation,} 6.0 \pm 3.6$ spikes/ sniff/s during stimulation; $p=0.04$, Wilcoxon signed rank test). Second, unlike the uniform enhancement of spontaneous spiking observed by optical stimulation of the $\mathrm{OB}, \mathrm{HDB}$ stimulation had mixed effects on individual units, with $\sim 60 \%$ of all cells showing at least some reduction in mean firing rate across the stimulation protocol (Fig. $5 F, G$ ). Third, at the population level, modulation by optical stimulation of HDB varied over the course of the stimulation period: during the initial 3-4 s of stimulation, MTCs exhibited an increase in mean (and median) firing rate, followed by a decrease in firing that persisted for the duration of stimulation (Fig. 5H). Thus, whereas we did not observe the uniform suppression of MTCs reported earlier with direct HDB optical stimulation (Ma and Luo, 2012), we found that activation of cholinergic neurons in HDB exerts a diversity of effects on MTC excitability that, at the MTC population level, are temporally complex over a prolonged activation period. This effect contrasts with the more uniform and sustained enhancement of MTC excitability evoked by direct optical excitation of cholinergic terminals within the OB.

\section{Discussion}

The basal forebrain cholinergic system is implicated in modulating sensory processing in diverse behavioral contexts, including wakefulness, learning, motivation, and attention (Hasselmo and Giocomo, 2006; Hasselmo and Sarter, 2011; Záborszky et al., 2012). In the olfactory system, cholinergic projections from basal forebrain to the olfactory bulb have been proposed to sharpen MTC receptive fields by suppressing spontaneous activity and weak excitation and enhancing inhibitory odorant responses (Chaudhury et al., 2009; D'Souza and Vijayaraghavan, 2012; Ma and Luo, 2012; Li and Cleland, 2013; de Almeida et al., 2013). Here, we found that local and specific activation of the axons of cholinergic neurons projecting from basal forebrain to the $\mathrm{OB}$ leads to a broad increase in the excitability of MTCs, broadly enhancing spontaneous and odorant-evoked MTC spiking responses and reducing or even reversing odorant-evoked inhibition. Increased MTC excitability was consistent across multiple experimental paradigms including different anesthetic regimens and different modes of ChR2 expression. In neocortical and thalamic sensory areas, cholinergic activation commonly facilitates sensory-evoked excitation, increasing the sensitivity, gain, or reliability of sensory responses (McKenna et al., 1988; Metherate et al., 1988; Disney et al., 2007; Herrero et al., 2008; Goard and Dan, 2009). Thus, although distinct from previous reports characterizing cholinergic modulation of odor coding in the $\mathrm{OB}$, our results are consistent with sensory enhancement effects of cholinergic modulation in other modalities.

Dissecting mechanisms of cholinergic modulation in vivo is complicated by the fact that cholinergic nuclei project to multiple brain areas that themselves are interconnected. HDB cholinergic neurons project directly to the $\mathrm{OB}$ as well as to the anterior olfactory nucleus and piriform and entorhinal cortices, each of which, 

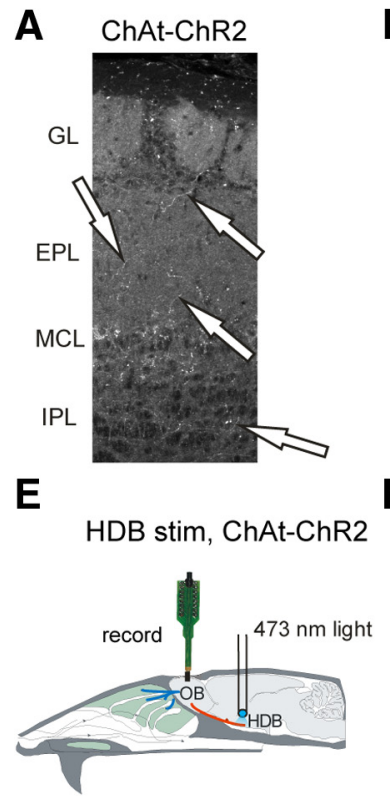

$F$
B
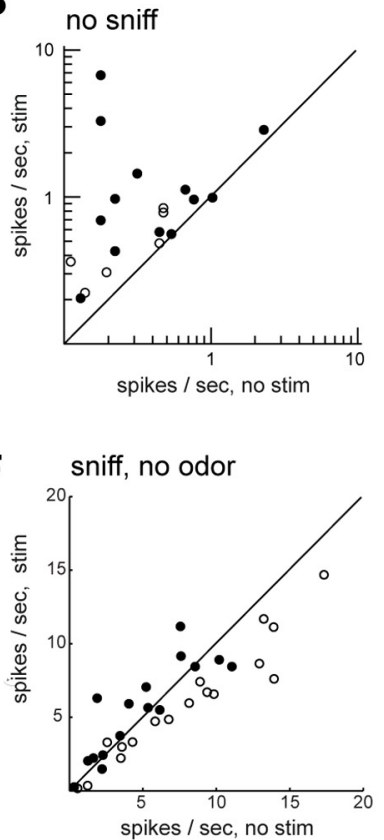

C

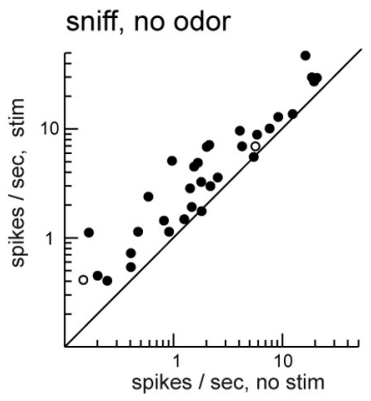

G

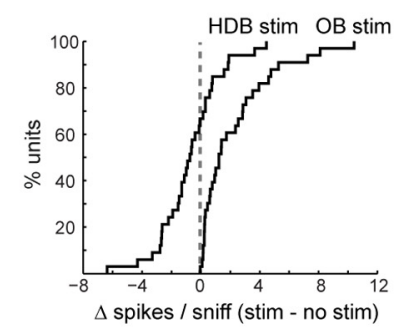

D

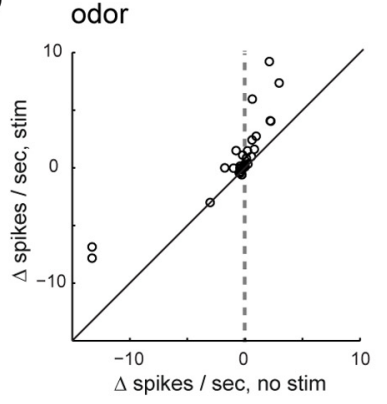

H

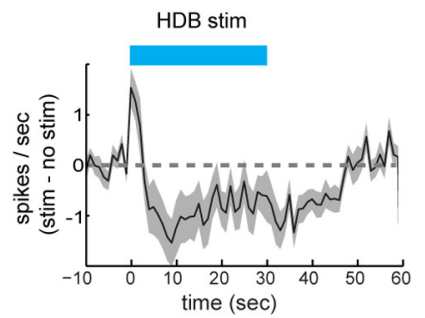

Figure 5. Enhanced MTC excitation by cholinergic OB inputs in ChAT-ChR2 mice. $A, O B$ section from a ChAT-ChR2 mouse showing weak Chr2-EYFP native fluorescence in sparsely distributed axon terminals in the OB (arrows). GL, glomerular layer; EPL, external plexiform layer; MCL, mitral cell layer; IPL, internal plexiform layer. $B$, Plot of spontaneous firing rate before (no stim) and during (stim) optical OB stimulation for MTCs $(n=24)$ recorded in ChAT-ChR2 transgenic mice, analyzed and plotted as in Figure 2B, showing an increase in MTC spiking during optical stimulation. C, Plot of inhalation-evoked peak firing rates during air inhalation before and during optical stimulation in ChAT-ChR2 mice ( $n=34$ units), analyzed and plotted as in Figure 3B. D, Plot of odorant-evoked changes in MTC spiking ( $\Delta$ spikes/s) in the absence (no stim) and during (stim) optogenetic stimulation in ChAT-ChR2 mice ( $n=33$ units). E, Schematic of experimental approach for optical stimulation of cholinergic neurons in HDB of ChAT-ChR2 mice. See Materials and Methods for details. F, Plot of MTC firing rates during air inhalation measured for the $30 \mathrm{~s}$ before and during optical stimulation of HDB in urethane-anesthetized ChAT-ChR2 mice ( $n=33$ units). Data are plotted on a linear scale to facilitate comparison with a similar dataset from Ma and Luo (2012). G, Cumulative probability plots comparing change in MTC firing rates caused by optical stimulation of $\mathrm{OB}$ or HDB. Plots reflect datasets plotted in $\boldsymbol{C}$ and $\boldsymbol{F}$, respectively. HDB stimulation reduces spike rates in $\sim 60 \%$ of units, whereas none are decreased by OB stimulation. $\boldsymbol{H}$, Time course of effects of optical stimulation on MTC spike rate during air inhalation, averaged across all units. The blue bar shows time of 30 s optical stimulation. The trace shows mean difference in the peak firing rate between trials with and without light stimulation, measured after each inhalation (at $1 \mathrm{~Hz}$ ); the shaded area indicates variance (SEM) around mean. Compare with Figure $3 \mathrm{H}$.

in turn, projects to the OB (Shipley and Adamek, 1984; Woolf et al., 1984; Záborszky et al., 1986, 2012). To obviate potential indirect basal forebrain modulation of $\mathrm{OB}$ activity, we used direct optogenetic activation of cholinergic axons arising from HDB; similar approaches have been used to investigate modulation of $\mathrm{OB}$ activity by centrifugal axons from olfactory cortex (Shipley and Adamek, 1984; Woolf et al., 1986; Boyd et al., 2012; Markopoulos et al., 2012) and GABAergic projections from HDB (Nunez-Parra et al., 2013). Selective activation of these axons regulated $\mathrm{OB}$ output by increasing MTC excitability and was dependent on cholinergic signaling in the $\mathrm{OB}$. This effect was qualitatively distinct from that of prolonged optogenetic stimulation of cholinergic neurons at their somata in HDB, which earlier was reported to suppress spontaneous MTC spiking (Ma and Luo, 2012) and in the present study evoked a temporally complex modulation consisting of an initial brief excitation followed by a modest suppression of MTC spiking.

Although the difference between our HDB stimulation results and those of $\mathrm{Ma}$ and Luo (2012) requires further investigation, the fact that direct stimulation of cholinergic OB inputs modulates $\mathrm{OB}$ activity distinctly from that of nonselectively activating cholinergic HDB neurons is consistent with the idea that indirect pathways from basal forebrain to the OB may differentially contribute to cholinergic modulation of early olfactory processing. For example, we observed labeling of cholinergic axons in both piriform cortex and anterior olfactory nucleus after viral expression in $\mathrm{HDB}$, and both of these secondary cortical areas can, in turn, modulate OB processing (Shipley and Adamek, 1984;
Woolf et al., 1986; Boyd et al., 2012; Markopoulos et al., 2012). Cholinergic activation may also excite GABAergic projections from basal forebrain to the $\mathrm{OB}$ as has recently been demonstrated for GABAergic projections to neocortex (Záborszky and Duque, 2000; Yang et al., 2014). These projections target OB granule cells and, potentially, other OB cell types (Gracia-Llanes et al., 2010; Nunez-Parra et al., 2013). Notably, nonselective electrical stimulation of HDB neurons also leads to increased MTC spontaneous activity (Kunze et al., 1991, 1992b; Zhan et al., 2013).

Technical differences in the optical stimulation of cholinergic neurons in $\mathrm{HDB}$ versus their axons in the $\mathrm{OB}$ may also contribute to their differential modulation of MTC spiking. First, highintensity, high-duty cycle light stimulation can lead to depolarization block at the somata of cholinergic neurons, suppressing firing (Witten et al., 2010; Herman et al., 2014). Second, optical stimulation of incoming axons has the potential to evoke nonphysiological levels of transmitter release via Chr2-mediated calcium influx or prolonged depolarization at the presynaptic terminal (Zhang and Oertner, 2007), although other studies have reported that optical versus electrical stimulation of ChR2expressing axons evokes similar (and apparently physiological) postsynaptic responses (Varga et al., 2009; Hagiwara et al., 2012; Nunez-Parra et al., 2013). Third, OB stimulation may activate cholinergic inputs to superficial glomerular layers more strongly than to deeper layers where cholinergic axons target granule cells, although we found that optical OB stimulation enhanced spontaneous spiking in MTCs in all preparations tested despite varying illumination intensity by a factor of $\sim 10(1-10 \mathrm{~mW})$. Finally, 
optical OB stimulation may activate a larger fraction of centrifugal cholinergic axons and do so more synchronously than stimulation of somata in HDB. Thus, whereas our results demonstrate that cholinergic inputs from basal forebrain to the $\mathrm{OB}$ enhance MTC excitation when activated in isolation, a full understanding of how basal forebrain activity modulates early olfactory processing requires greater knowledge of the multiple circuit pathways connecting these structures and the nature of their ongoing activity patterns during behavior.

\section{Functional role of bulbar cholinergic modulation}

Bulbar cholinergic activation increased spontaneous MTC spiking in the absence of inhalation-driven sensory input and caused broad enhancement of odorant-evoked spiking responses. Thus, cholinergic projections to the OB play a role in setting excitatory tone as well as shaping odor representations at the level of $\mathrm{OB}$ output. Notably, and in contrast to earlier predictions, we found that bulbar cholinergic signaling enhanced MTC responses to both weakly and strongly effective odorants. Indeed, OB stimulation increased odorant-evoked spike rates even when the evoked response was suppressive or null, an effect that should lead to broader receptive fields across a range of odorants. This increased MTC sensitivity and broader odorant-evoked excitation may be adaptive for processing olfactory input during periods of heightened attention by increasing the signal-to-noise ratio of odorant-evoked activity patterns. Any reduction in discriminative power associated with broader MTC receptive fields may be modest given the capacity of the olfactory system to encode odor information (Koulakov et al., 2007; Smear et al., 2013) and could be outweighed by the increased salience of olfactory cues for driving odor-guided behaviors (Mandairon et al., 2006). Cholinergic enhancement of $\mathrm{OB}$ output may also play a role in acetylcholine-dependent olfactory learning by enhancing the strength of $\mathrm{OB}$ signaling to cortex or the synchrony of MTC spiking in the $\gamma$ frequency range (Ravel et al., 1994; Fletcher and Chen, 2010; Hasselmo and Sarter, 2011; Li and Cleland, 2013).

Our results are consistent with a dynamic role for the cholinergic system in modulating early sensory processing during behavior. In neocortex of awake animals, periods of heightened sensory attention correlate with transient increases in acetylcholine levels lasting several seconds (Parikh et al., 2007). Cholinergic basal forebrain neurons also show transient spike bursts during active waking states, along with slower changes in mean firing rates between different waking states (Lee et al., 2005). We found that activation of cholinergic inputs to the $\mathrm{OB}$ evoked rapid increases in MTC excitability that roughly followed the time course of cholinergic activation, whereas prolonged activation of cholinergic neurons in HDB led to mixed modulation. Thus, transient cholinergic activation may increase MTC sensitivity, whereas sustained activation may subsequently suppress some MTCs, potentially allowing only stronger sensory cues to reach cortical processing areas.

\section{Circuit mechanisms underlying bulbar cholinergic modulation}

The circuit mechanisms underlying the cholinergic enhancement of MTC excitability remain to be elucidated. Cholinergic axons from HDB are reported to synapse primarily on GABAergic neurons throughout the OB (Kasa et al., 1995), suggesting that a primary mode of action may be to modulate the strength of inhibition in OB circuits. Brief electrical stimulation of HDB leads to granule cell inhibition and concomitant facilitation of MTC spiking in vivo (Kunze et al., 1992a,b; Zhan et al., 2013), and muscarinic ACh receptor ( $\mathrm{mAchR}$ ) activation can inhibit granule and short axon cells in OB slices (Castillo et al., 1999; Pignatelli and Belluzzi, 2008). However, several OB slice studies have reported that mAchR activation enhances granule cell excitation leading to suppression of MTC excitability (Pressler et al., 2007; Smith and Araneda, 2010), and periglomerular or short axon cells may also be excited by muscarinic activation (M. Shipley, unpublished observations). Cholinergic fibers may also impact additional $\mathrm{OB}$ circuits, e.g., external plexiform layer interneurons that provide broad inhibitory input to MTCs (Huang et al., 2013; Kato et al., 2013; Miyamichi et al., 2013). Finally, cholinergic inputs may increase MTC excitability via nicotinic ACh receptors (nAchRs) expressed on MTCs or on external tufted cells (Castillo et al., 1999; D'Souza et al., 2013). However, nAchRs desensitize rapidly and can also drive feedback inhibition onto MTCs and external tufted cells (D'Souza and Vijayaraghavan, 2012; D'Souza et al., 2013), so their contribution to modulating OB circuits during behavior may depend on the dynamics of cholinergic activity as well as basal cholinergic tone. Additional studies dissecting the impact of cholinergic modulation on genetically and anatomically defined cell types are needed to more fully understand the circuit mechanisms underlying cholinergic modulation of $\mathrm{OB}$ output. Addressing these questions in the awake, behaving animal is critical to fully understanding the dynamic nature of $\mathrm{OB}$ processing in the context of active sensing.

\section{References}

Boyd AM, Sturgill JF, Poo C, Isaacson JS (2012) Cortical feedback control of olfactory bulb circuits. Neuron 76:1161-1174. CrossRef Medline

Bozza T, McGann JP, Mombaerts P, Wachowiak M (2004) In vivo imaging of neuronal activity by targeted expression of a genetically encoded probe in the mouse. Neuron 42:9-21. CrossRef Medline

Carey RM, Wachowiak M (2011) Effect of sniffing on the temporal structure of mitral/tufted cell output from the olfactory bulb. J Neurosci 31: 10615-10626. CrossRef Medline

Carey RM, Verhagen JV, Wesson DW, Pírez N, Wachowiak M (2009) Temporal structure of receptor neuron input to the olfactory bulb imaged in behaving rats. J Neurophysiol 101:1073-1088. Medline

Carlsen J, Záborszky L, Heimer L (1985) Cholinergic projections from the basal forebrain to the basolateral amygdaloid complex: a combined retrograde fluorescent and immunohistochemical study. J Comp Neurol 234:155-167. CrossRef Medline

Castillo PE, Carleton A, Vincent JD, Lledo PM (1999) Multiple and opposing roles of cholinergic transmission in the main olfactory bulb. J Neurosci 19:9180-9191. Medline

Chaudhury D, Escanilla O, Linster C (2009) Bulbar acetylcholine enhances neural and perceptual odor discrimination. J Neurosci 29:52-60. CrossRef Medline

Cleland TA, Morse A, Yue EL, Linster C (2002) Behavioral models of odor similarity. Behav Neurosci 116:222-231. CrossRef Medline

Courtiol E, Amat C, Thévenet M, Messaoudi B, Garcia S, Buonviso N (2011) Reshaping of bulbar odor response by nasal flow rate in the rat. PLoS One 6:e16445. CrossRef Medline

de Almeida L, Idiart M, Linster C (2013) A model of cholinergic modulation in olfactory bulb and piriform cortex. J Neurophysiol 109:1360-1377. CrossRef Medline

Disney AA, Aoki C, Hawken MJ (2007) Gain modulation by nicotine in macaque V1. Neuron 56:701-713. CrossRef Medline

Doty RL, Bagla R, Kim N (1999) Physostigmine enhances performance on an odor mixture discrimination test. Physiol Behav 65:801-804. Medline

D'Souza RD, Vijayaraghavan S (2012) Nicotinic receptor-mediated filtering of mitral cell responses to olfactory nerve inputs involves the $\alpha 3 \beta 4$ subtype. J Neurosci 32:3261-3266. CrossRef Medline

D'Souza RD, Parsa PV, Vijayaraghavan S (2013) Nicotinic receptors modulate olfactory bulb external tufted cells via an excitation-dependent inhibitory mechanism. J Neurophysiol 110:1544-1553. CrossRef Medline

Fletcher ML, Chen WR (2010) Neural correlates of olfactory learning: critical role of centrifugal neuromodulation. Learn Mem 17:561-570. CrossRef Medline 
Goard M, Dan Y (2009) Basal forebrain activation enhances cortical coding of natural scenes. Nat Neurosci 12:1444-1449. CrossRef Medline

Gracia-Llanes FJ, Crespo C, Blasco-Ibáñez JM, Nacher J, Varea E, RoviraEsteban L, Martínez-Guijarro FJ (2010) GABAergic basal forebrain afferents innervate selectively GABAergic targets in the main olfactory bulb. Neuroscience 170:913-922. CrossRef Medline

Grosmaitre X, Santarelli LC, Tan J, Luo M, Ma M (2007) Dual functions of mammalian olfactory sensory neurons as odor detectors and mechanical sensors. Nat Neurosci 10:348-354. CrossRef Medline

Hagiwara A, Pal SK, Sato TF, Wienisch M, Murthy VN (2012) Optophysiological analysis of associational circuits in the olfactory cortex. Front Neural Circuits 6:18.

Hasselmo ME, Giocomo LM (2006) Cholinergic modulation of cortical function. J Mol Neurosci 30:133-135. CrossRef Medline

Hasselmo ME, Sarter M (2011) Modes and models of forebrain cholinergic neuromodulation of cognition. Neuropsychopharmacology 36:52-73. CrossRef Medline

Herman AM, Huang L, Murphey DK, Garcia I, Arenkiel BR, Calabrese RL (2014) Cell type-specific and time-dependent light exposure contribute to silencing in neurons expressing Channelrhodopsin-2. eLife 3:e01481.

Herrero JL, Roberts MJ, Delicato LS, Gieselmann MA, Dayan P, Thiele A (2008) Acetylcholine contributes through muscarinic receptors to attentional modulation in V1. Nature 454:1110-1114. CrossRef Medline

Huang L, Garcia I, Jen HI, Arenkiel BR (2013) Reciprocal connectivity between mitral cells and external plexiform layer interneurons in the mouse olfactory bulb. Front Neural Circuits 7:32. CrossRef Medline

Kalmbach A, Hedrick T, Waters J (2012) Selective optogenetic stimulation of cholinergic axons in neocortex. J Neurophysiol 107:2008-2019. CrossRef Medline

Kasa P, Hlavati I, Dobo E, Wolff A, Joo F, Wolff JR (1995) Synaptic and non-synaptic cholinergic innervation of the various types of neurons in the main olfactory bulb of adult rat: immunocytochemistry of choline acetyltransferase. Neuroscience 67:667-677. CrossRef Medline

Kato HK, Chu MW, Isaacson JS, Komiyama T (2012) Dynamic sensory representations in the olfactory bulb: modulation by wakefulness and experience. Neuron 76:962-975. CrossRef Medline

Kato HK, Gillet SN, Peters AJ, Isaacson JS, Komiyama T (2013) Parvalbumin-expressing interneurons linearly control olfactory bulb output. Neuron 80:1218-1231. CrossRef Medline

Kolisnyk B, Guzman MS, Raulic S, Fan J, Magalhães AC, Feng G, Gros R, Prado VF, Prado MA (2013) ChAT-ChR2-EYFP mice have enhanced motor endurance but show deficits in attention and several additional cognitive domains. J Neurosci 33:10427-10438. CrossRef Medline

Koulakov A, Gelperin A, Rinberg D (2007) Olfactory coding with all-ornothing glomeruli. J Neurophysiol 98:3134-3142. CrossRef Medline

Kunze WA, Shafton AD, Kemm RE, McKenzie JS (1991) Effect of stimulating the nucleus of the horizontal limb of the diagonal band on single unit activity in the olfactory bulb. Neuroscience 40:21-27. CrossRef Medline

Kunze WA, Shafton AD, Kem RE, McKenzie JS (1992a) Intracellular responses of olfactory bulb granule cells to stimulating the horizontal diagonal band nucleus. Neuroscience 48:363-369. CrossRef Medline

Kunze WA, Shafton AD, Kemm RE, McKenzie JS (1992b) Olfactory bulb output neurons excited from a basal forebrain magnocellular nucleus. Brain Res 583:327-331. CrossRef Medline

Lee MG, Hassani OK, Alonso A, Jones BE (2005) Cholinergic basal forebrain neurons burst with theta during waking and paradoxical sleep. J Neurosci 25:4365-4369. CrossRef Medline

Li G, Cleland TA (2013) A Two-layer biophysical model of cholinergic neuromodulation in olfactory bulb. J Neurosci 33:3037-3058. CrossRef Medline

Linster C, Wyble BP, Hasselmo ME (1999) Electrical stimulation of the horizontal limb of the diagonal band of broca modulates population EPSPs in piriform cortex. J Neurophysiol 81:2737-2742. Medline

Ma M, Luo M (2012) Optogenetic activation of basal forebrain cholinergic neurons modulates neuronal excitability and sensory responses in the main olfactory bulb. J Neurosci 32:10105-10116. CrossRef Medline

Madisen L, Zwingman TA, Sunkin SM, Oh SW, Zariwala HA, Gu H, Ng LL, Palmiter RD, Hawrylycz MJ, Jones AR, Lein ES, Zeng H (2010) A robust and high-throughput Cre reporting and characterization system for the whole mouse brain. Nat Neurosci 13:133-140. CrossRef Medline

Mandairon N, Ferretti CJ, Stack CM, Rubin DB, Cleland TA, Linster C (2006) Cholinergic modulation in the olfactory bulb influences sponta- neous olfactory discrimination in adult rats. Eur J Neurosci 24:32343244. CrossRef Medline

Mandairon N, Peace S, Karnow A, Kim J, Ennis M, Linster C (2008) Noradrenergic modulation in the olfactory bulb influences spontaneous and reward-motivated discrimination, but not the formation of habituation memory. Eur J Neurosci 27:1210-1219. CrossRef Medline

Markopoulos F, Rokni D, Gire DH, Murthy VN (2012) Functional properties of cortical feedback projections to the olfactory bulb. Neuron 76 : 1175-1188. CrossRef Medline

Mattis J, Tye KM, Ferenczi EA, Ramakrishnan C, O'Shea DJ, Prakash R, Gunaydin LA, Hyun M, Fenno LE, Gradinaru V, Yizhar O, Deisseroth K (2012) Principles for applying optogenetic tools derived from direct comparative analysis of microbial opsins. Nat Methods 9:159-172. CrossRef Medline

McGann JP, Pírez N, Gainey MA, Muratore C, Elias AS, Wachowiak M (2005) Odorant representations are modulated by intra- but not interglomerular presynaptic inhibition of olfactory sensory neurons. Neuron 48:1039-1053. CrossRef Medline

McKenna TM, Ashe JH, Hui GK, Weinberger NM (1988) Muscarinic agonists modulate spontaneous and evoked unit discharge in auditory cortex of cat. Synapse 2:54-68. CrossRef Medline

Metherate R, Tremblay N, Dykes RW (1988) The effects of acetylcholine on response properties of cat somatosensory cortical neurons. J Neurophysiol 59:1231-1252. Medline

Miyamichi K, Shlomai-Fuchs Y, Shu M, Weissbourd BC, Luo L, Mizrahi A (2013) Dissecting local circuits: parvalbumin interneurons underlie broad feedback control of olfactory bulb output. Neuron 80:1232-1245. CrossRef Medline

Nunez-Parra A, Maurer RK, Krahe K, Smith RS, Araneda RC (2013) Disruption of centrifugal inhibition to olfactory bulb granule cells impairs olfactory discrimination. Proc Natl Acad Sci U S A 110:14777-14782. CrossRef Medline

Parikh V, Sarter M (2008) Cholinergic mediation of attention: contributions of phasic and tonic increases in prefrontal cholinergic activity. Ann N Y Acad Sci 1129:225-235. CrossRef Medline

Parikh V, Kozak R, Martinez V, Sarter M (2007) Prefrontal acetylcholine release controls cue detection on multiple timescales. Neuron 56:141154. CrossRef Medline

Petzold GC, Hagiwara A, Murthy VN (2009) Serotonergic modulation of odor input to the mammalian olfactory bulb. Nat Neurosci 12:784-791. CrossRef Medline

Pignatelli A, Belluzzi O (2008) Cholinergic modulation of dopaminergic neurons in the mouse olfactory bulb. Chem Senses 33:331-338. CrossRef Medline

Pírez N, Wachowiak M (2008) In vivo modulation of sensory input to the olfactory bulb by tonic and activity-dependent presynaptic inhibition of receptor neurons. J Neurosci 28:6360-6371. CrossRef Medline

Pressler RT, Inoue T, Strowbridge BW (2007) Muscarinic receptor activation modulates granule cell excitability and potentiates inhibition onto mitral cells in the rat olfactory bulb. J Neurosci 27:10969-10981. CrossRef Medline

Ravel N, Elaagouby A, Gervais R (1994) Scopolamine injection into the olfactory bulb impairs short-term olfactory memory in rats. Behav Neurosci 108:317-324. CrossRef Medline

Rossi J, Balthasar N, Olson D, Scott M, Berglund E, Lee CE, Choi MJ, Lauzon D, Lowell BB, Elmquist JK (2011) Melanocortin-4 receptors expressed by cholinergic neurons regulate energy balance and glucose homeostasis. Cell Metab 13:195-204. CrossRef Medline

Sarter M, Hasselmo ME, Bruno JP, Givens B (2005) Unraveling the attentional functions of cortical cholinergic inputs: interactions between signal-driven and cognitive modulation of signal detection. Brain Res Rev 48:98-111. CrossRef Medline

Shipley MT, Adamek GD (1984) The connections of the mouse olfactory bulb: a study using orthograde and retrograde transport of wheat germ agglutinin conjugated to horseradish peroxidase. Brain Res Bull 12:669_ 688. CrossRef Medline

Smear M, Resulaj A, Zhang J, Bozza T, Rinberg D (2013) Multiple perceptible signals from a single olfactory glomerulus. Nat Neurosci 16:16871691. CrossRef Medline

Smith RS, Araneda RC (2010) Cholinergic modulation of neuronal excitability in the accessory olfactory bulb. J Neurophysiol 104:2963-2974. CrossRef Medline 
Spors H, Wachowiak M, Cohen LB, Friedrich RW (2006) Temporal dynamics and latency patterns of receptor neuron input to the olfactory bulb. J Neurosci 26:1247-1259. CrossRef Medline

Varga V, Losonczy A, Zemelman BV, Borhegyi Z, Nyiri G, Domonkos A, Hangya B, Holderith N, Magee JC, Freund TF (2009) Fast synaptic subcortical control of hippocampal circuits. Science 326:449-453. CrossRef Medline

Verhagen JV, Wesson DW, Netoff TI, White JA, Wachowiak M (2007) Sniffing controls an adaptive filter of sensory input to the olfactory bulb. Nat Neurosci 10:631-639. CrossRef Medline

Wachowiak M, Cohen LB (2001) Representation of odorants by receptor neuron input to the mouse olfactory bulb. Neuron 32:723-735. CrossRef Medline

Witten IB, Lin SC, Brodsky M, Prakash R, Diester I, Anikeeva P, Gradinaru V, Ramakrishnan C, Deisseroth K (2010) Cholinergic interneurons control local circuit activity and cocaine conditioning. Science 330:16771681. CrossRef Medline

Woolf NJ, Eckenstein F, Butcher LL (1984) Cholinergic systems in the rat brain: I. projections to the limbic telencephalon. Brain Res Bull 13:751784. CrossRef Medline

Woolf NJ, Hernit MC, Butcher LL (1986) Cholinergic and non-cholinergic projections from the rat basal forebrain revealed by combined choline acetyltransferase and Phaseolus vulgaris leucoagglutinin immunohistochemistry. Neurosci Lett 66:281-286. CrossRef Medline

Yang C, McKenna JT, Zant JC, Winston S, Basheer R, Brown RE (2014)
Cholinergic neurons excite cortically projecting basal forebrain GABAergic neurons. J Neurosci 34:2832-2844. CrossRef Medline

Záborszky L, Duque A (2000) Local synaptic connections of basal forebrain neurons. Behav Brain Res 115:143-158. CrossRef Medline

Záborszky L, Carlsen J, Brashear HR, Heimer L (1986) Cholinergic and GABAergic afferents to the olfactory bulb in the rat with special emphasis on the projection neurons in the nucleus of the horizontal limb of the diagonal band. J Comp Neurol 243:488-509. CrossRef Medline

Z'aborszky L, Van den Pol AN, Gyengesi E (2012) The basal forebrain cholinergic projection system in mice. In: The mouse nervous system (Watson C, Paxinos G, Puelles L, eds), pp 684-718. Amsterdam: Elsevier.

Zhan X, Yin P-b, Heinbockel T (2013) The basal forebrain modulates spontaneous activity of principal cells in the main olfactory bulb of anesthetized mice. Front Neural Circuits 7:148. CrossRef Medline

Zhang YP, Oertner TG (2007) Optical induction of synaptic plasticity using a light-sensitive channel. Nat Methods 4:139-141. CrossRef Medline

Zhao S, Ting JT, Atallah HE, Qiu L, Tan J, Gloss B, Augustine GJ, Deisseroth K, Luo M, Graybiel AM, Feng G (2011) Cell type-specific channelrhodopsin-2 transgenic mice for optogenetic dissection of neural circuitry function. Nat Methods 8:745-752. CrossRef Medline

Zimmer LA, Ennis M, Shipley MT (1999) Diagonal band stimulation increases piriform cortex neuronal excitability in vivo. Neuroreport 10: 2101-2105. CrossRef Medline 